\title{
Axillary Lymphadenopathy that Suggestive Breast Cancer Recurrence: A Case Report
}

\section{Meme Kanseri Nüksünü Düşündüren Aksiller Lenfadenopati: Olgu Sunumu}

\author{
Fatma Buğdaycı Başal ${ }^{1}$, Umut Demirci ${ }^{1}$, Mehmet Doğan ${ }^{2}$, Lütfi Doğan ${ }^{3}$, Ayşe Demirci ${ }^{1}$, Hülya \\ Efetürk $^{4}$, Tahsin Özatıı ${ }^{1}$, Havva Yeşil Çınkır ${ }^{1}$, Ömür Berna Öksüzoğlu Çakmak ${ }^{1}$ \\ ${ }^{1}$ Dr. A. Y. Ankara Onkoloji Eğitim Araştırma Hastanesi, Tıbbi Onkoloji Kliniği \\ ${ }^{2}$ Dr. A. Y. Ankara Onkoloji Eğitim Araştırma Hastanesi, Tıbbi Patoloji Kliniği \\ ${ }^{3}$ Dr. A. Y. Ankara Onkoloji Eğitim Araştırma Hastanesi, Nükleer Tıp Kliniği \\ ${ }^{4}$ Dr. A. Y. Ankara Onkoloji Eğitim Araştırma Hastanesi, Genel Cerrahi Kliniği
}

Doi: 10.5505/aot.2012.27928

\section{ÖZET}

Meme kanseri kadınlarda kansere bağlı ölümlerde ilk sırada yerini almaktadır. Mortalitenin en sık sebebi ise nüks hastalıktır. Biz bu olguda meme kanseri nedeniyle remisyonda izlenirken diğer memede bölgesel yeni gelişen lenfadenopatilerle nüks düşünülen fakat granülomatöz lenfadenit tanısı alan bir hastayı sunduk.

Anahtar Kelimeler: Meme karsinomu; Aksiller lenfadenopati; Granülomatöz lenfadenit

\begin{abstract}
Breast cancer is the most common cause of cancer related death in women. The most common cause of mortality is recurrent diseases. We report the case of a patient followed-up with breast cancer under remission presented with newly developed regional lymphadenopathy on the axillary region of the other breast side, which was suspected as the recurrence of the disease and diagnosed as granulomatosus lymphadenitis.
\end{abstract}

Key words: Breast cancer; Axillary lymphadenopathy; Granulomatous lymphadenitis

\section{Giriş}

Meme kanseri kadınlarda kansere bağlı ölümlerde ilk sırada yerini almaktadır. Mortalitenin en sık sebebi ise nüks hastalıktır. Prognostik faktörlere bağlı olarak lenf nodu negatif hastalarda \%30, lenf nodu pozitif hastalarda \%70'lere ulaşan oranlarda nüks gözlenebileceği bildirilmiştir (1).

Granülomatöz hastalıklar tekrarlayan bakteriyel ve fungal enfeksiyonların yanı sira sarkoidoz, wegener granülomatozu, infeksiyonlar ve bazı malignitelere sekonder olarak vücudun herhangi bir bölgesinde granülomatöz reaksiyonla ortaya çıkan kronik hastalıklardır (2-4). Biz bu olguda meme kanseri nedeniyle remisyonda izlenirken diğer memede bölgesel yeni gelişen lenfadeno-patilerle (LAP) nüks düşünülen fakat granülomatöz lenfadenit tanısı alan bir hastayı sunduk.

\section{Olgu Sunumu}

Altmış yaşında kadın hasta diabetes mellitus, hipertansiyon, dislipidemi, koroner arter hastalığı gibi komorbid hastalıklarla takip edilirken 2007 yılında sa $\breve{g}$ meme kitle biyopsisinde; infiltratif duktal karsinom, grad 3, hormon reseptörü kuvvetli pozitif ve HER-2 negatif hastalık saptanmıştı. Şubat 2007'de sağ modifiye radikal mastektomi ve aksiller lenf nodu disseksiyonu yapıld1. T1 tümörü $(1.2 \mathrm{~cm})$ mevcut olan hastanın bir lenf nodunda tümör invazyonu mevcuttu. Evre 2A hastalık nedeni ile adjuvan 6 kür siklofosfamid+ adriyamisin+ 5FU almıştı. Adjuvan kemoterapiler sonrası cerrahi postmenopozal olan hastanın adjuvan aromataz inhibitörü tedavisi 2012 yılında bitmişti. Özgeçmişinde 2004 yılında sağ maksiller bölge derisinden bazal hücreli karsinom eksize edilmişti. Soygeçmişinde bir kardeşi lösemiden kaybedilmişti. Remisyonda izlenirken 2 y1l sonra yapilan kontrolünde meme ultrasonografisinde (US) ve mammo- 
grafisinde $(\mathrm{MG})$ sol superior toraks duvarında pektoral kas derininde $18 \mathrm{~mm}$ ve $30 \mathrm{~mm}$ LAP ve sol aksiller LAP saptand. Hastaya 7 ay önce koroner stent uygulanması nedeni ile meme manyetik rezonans görüntülemesi (MRG) yapılamadi. Pozitron emisyon tomografi- bilgisayarlı tomografisinde (PETBT) sol meme pektoral kas gruplarında lenf paketleri tarzında 2 cm'yi aşan LAP'lar (SUVm: 7.15) ve sol aksiller lojda $1 \mathrm{~cm}$ 'yi aşan LAP'lar (SUVm: 4.55) tespit edildi (Resim 1). Pektoral kas içindeki lenf nodlarının en büyügünden tru-cut biopsi yapıldı. Öncelikle nüks düşünülen hastanın aynı zamanda cerrahi için hazırlıkları planlanmaktaydi. Fakat sol aksiler LAP ve sol meme pektoral kas komşu LAP'lardan yapılan iki biyopsi sonucunda da granülomatöz lenfadenit saptand1 (Resim 2). Bu nedenle ayırıcı tanı için gögüs hastalıkları ile konsülte edildi.

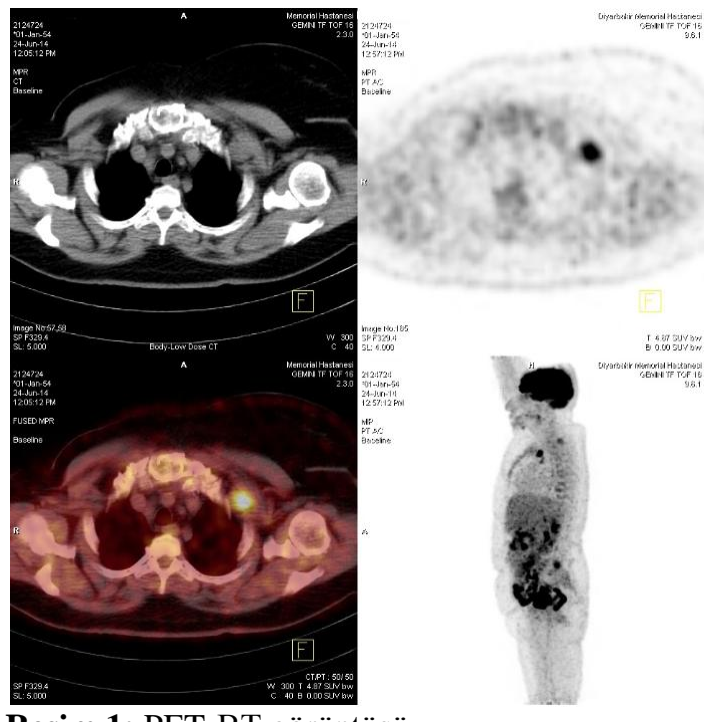

Resim 1: PET-BT görüntüsü

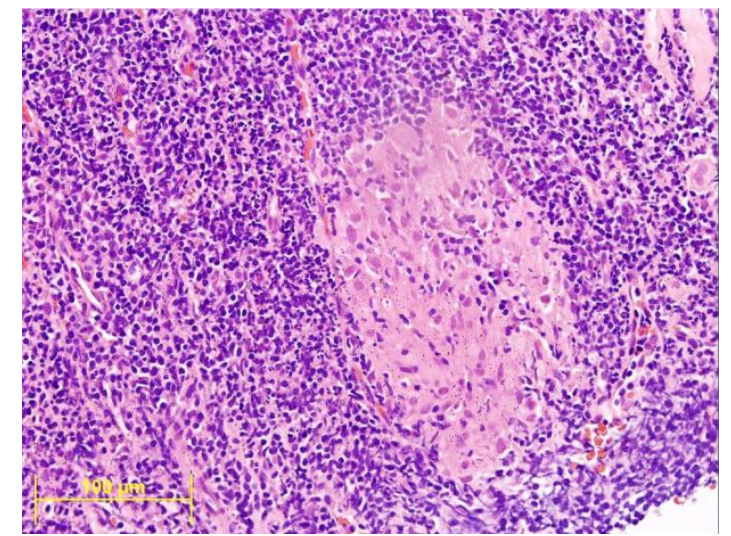

Resim 2: Hematoksilen eozin boyama $x 400$ büyütme

\section{Tartışma}

Tanısının 7. yilında remisyonda izlenen meme kanserli olgumuz sol memede saptanan herhangi bir kitle olmamasına rağmen sol pektoral kas içinde ve sol aksillada LAP saptanması nedeniyle öncelikle ikinci primer okült meme kanseri ve/ veya nüks lenf nodu metastatik meme kanseri düşünüldü. Fakat pektoral kas içindeki en büyük lenf nodundan alınan biyopsi sonucunda kazeifikasyon nekrozu izlenmeyen granülomatöz lenfadenit saptanması üzerine granülomatöz hastalığın etyolojisi araştırılmaya başlandı.

Tüberkülöz, sarkoidoz, idiopatik granülomatöz mastit, bakteriyel ve fungal hastalıklar gibi diğer granülomatöz hastalıklar ayırıcı tanıda düşünülmelidir. İdiopatik granülomatöz mastit memenin inflamatuar bir hastalığı olup memede kitle, fistül ve aksillada LAP ile seyreden, maligniteyi taklit eden, etyolojisi bilinmeyen bir hastalıktır. Genç yaş ve emziren kadınlarda daha sık görülür (5). Hastamız memesinde lezyon olmaması ve ileri yaşta olması ile bu tanıdan uzaklaşılmıştır. Sarkoidoz nedeni bilinmeyen vücutta LAP'lar ile seyreden birden fazla organı tutabilen sistemik bir hastalıktır. Memenin primer sarkoidozu da literatürde bildirilmiştir (6). Memede saptandığında malignensi ile karışsa da sarkoidoz tanısı maligniteyi dışlamaz. Çünkü memede malignite sarkoidozdan çok daha fazla görülmektedir (6). Bizim olgumuz da akciğer ve göz tutulumu olmaması ile sarkoidoz tanısından uzaklaşılmıştır.

Meme tüberkülozu oldukça nadir görülen bir klinik prezantasyon olup insidansı \%0.1-0.5 arasında değişmektedir. Primer ve sekonder olarak iki formda görülür. Direk yada hematojen yolla yayılır (7). Aksiller lenf nodlarına retrograd yolla yayılır. Meme USG, MG ve BT görüntülerinde memede lezyonlar saptanabilir. Direk yayılım ile deri lezyonları tanıya ulaşmada yardımcıdır (8). Patolojisinde Langhans dev hücreleri ve kazeifikasyon nekrozu patognomoniktir. Aside dirençli basiller görülebilir (5). Olgumuzun PPD değeri $20 \mathrm{~mm}$ olarak ölçülmüş olup Ziehl-Neelsen boyamasında dokuda aside dirençli basil görülmemiştir.

Tüberküloz lenfadeniti ekstrapulmoner tüberkülozun en s1k prezantasyonudur ve \%43 oranında periferik LAP'lar ile görülür (9). İzole periferal tüberküloz lenfadenopatisi 
genellikle hastalık reaktivasyonuna bağlıdır fakat başlangıçta genellikle asemptomatiktir (10). PET-BT'de FDG tutulumu olmas1 itibariyle çoğunlukla malignite olarak değerlendirilse de yapılan biyopsiler sonucu ekstrapulmoner tüberküloz lenfadeniti tanısı konur (11). PET-BT'de memede FDG tutulumu akut ve kronik enfeksiyöz mastitlerde ve cerrahi sonrasi hemorajik inflamasyonda görülen ve maligniteyi taklit eden durumlardır (12). Ayrıca okült meme karsinomu PETBT'de saptanabilir fakat duyarlılığ düşüktür (12). Bizim olgumuzda PET-BT'de memede tutulum olmamakla birlikte lenf nodlarında tutulum elde edilmiştir. Okült meme karsinomu memede palpabl kitle olmadan aynı taraf aksillada LAP ile de kliniğe yansıyabilen, MG yada meme US ile kitle tespit edilemeyen bir hastal1ktır. Y1ll1k insidans1 \%0.3-1 arasinda değişmektedir (13). Meme MRG ve PET-BT kitlenin tespit edilmesinde değerli tetkiklerdir. PET-BT'nin duyarlılığının düşük olması ve yanlış negatiflikler (özellikle iyi diferansiye ve $1 \mathrm{~cm}$ altı tümörlerde) nedeniyle rutinde önerilen bir tetkik değildir (12).

Meme kanseri nükslerinin \%10-20'sini lokorejyonel nüksler oluştururken \%60-70'ini uzak metastazlar oluşturur. Nüks riski ilk 2-3 yıl içinde en yüksek iken zamanla azalır (14). Mastektomi uygulanmış lokorejyonel nükslü hastaların \%30-40'inda da aksiller, supraklavikular ve internal mamarian lenf nodlarında rejyonel nüks gözlenir (15). Lenf nodu tutulumu ile kliniğe yansıyan nükslerde ayırıc1 tanıda LAP yapan sebeplerin de akılda tutulması önemli bir noktadır. Nitekim olgumuzda görüldüğü gibi LAP'ların benign yada malign birçok farklı sebebi olabilir.

\section{Çıkar Çatışması: Yok}

\section{Kaynaklar}

1. Cardoso F, Castiglione M; ESMO Guidelines Working Group. Locally recurrent or metastatic breast cancer: ESMO clinical recommendations for diagnosis, treatment and follow-up. Ann Oncol 2009;20 Suppl 4:15-8

2. Dorman SE, Guide SV, Conville PS, et al. Nocardia infection in chronic granulomatous disease. Clin Infect Dis 2002;35:390-4

3. Segal BH, DeCarlo ES, Kwon-Chung KJ, Malech HL, Gallin JI, Holland SM. Aspergillus nidulans infection in chronic granulomatous disease. Medicine (Baltimore) 1998;77:345-54

4. Niitsu H, Tanabe K, Tokumoto N, et al. Idiopathic granulomatous gastritis resembling a gastrointestinal stromal tumor. Case Rep Gastroenterol 2012;6:502-9

5. Seo HR, Na KY, Yim HE, et al. Differential diagnosis in idiopathic granulomatous mastitis and tuberculous mastitis. J Breast Cancer 2012;15:111-8

6. Isley LM, Cluver AR, Leddy RJ, Baker MK. Primary sarcoid of the breast with incidental malignancy. J Clin Imaging Sci 2012;2:46

7. Meggiorini ML, Vitolo D, Russo A, Trinchieri V, De Felice C. Breast tuberculosis: rare but still present in Italy--a case of mycobacterium breast infection. Breas Dis 2011-2012;33:177-82

8. Kervancioğlu S, Kervancioğlu R, Ozkur A, Sirikçi A. Primary tuberculosis of the breast. Diagn Interv Radiol 2005;11:210-2

9. Dandapat MC, Mishra BM, Dash SP, Kar PK. Peripheral lymph node tuberculosis: a review of 80 cases. Br J Surg 1990;77:911-2

10. Biadglegne F, Tesfaye W, Sack U, Rodloff AC. Tuberculous lymphadenitis in northern ethiopia: in a public health and microbiological perspectives. PLoS One 2013;8:e81918

11. Alan Selçuk N, Fenercioğlu A, Selçuk HH, Uluçay C, Yencilek E. Multifoci Bone Tuberculosis and Lymphadenitis in Mediastinum Mimics Malignancy on FDG-PET/CT: A Case Report. Mol Imaginig Radionucl Ther 2014;23:39-42

12. Banzo J, Ubieto MA, González C, et al. Papillary thyroid carcinoma synchronous with breast cancer: an incidental finding in an (18)F-FDG PET-CT study carried out in a search for occult breast cancer. Rev.Esp Med Nucl Imagen Mol 2012;31:213-5

13. Woo SM, Son BH, Lee JW, et al. Survival outcomes of different treatment methods for the ipsilateral breast of occult breast cancer patients with axillary lymph node metastasis: a single center experience. J. Breast Cancer 2013;16:410-6

14. Gerber B, Freund M, Reimer T. Recurrent breast cancer: treatment strategies for maintaining and prolonging good quality of life. Dtsch Arztebl Int. 2010;107:85-91

15. Solin LJ, Haris ER, Weinstein SP, DeMichele A, Tchou J. Local Regional Recurrence After Breast Conservation Treatment or Mastectomy In: Harris JR, Lippman ME, Morrow M, Os-borne CK, eds. The disease of breast. 4th ed. Lippincott Williams \& Wilkins; 2010.p.840-55 